\title{
Understanding alveolarization to induce lung regeneration
}

\author{
José Alberto Rodríguez-Castillo1, David Bravo Pérez', Aglaia Ntokou', Werner Seeger ${ }^{1,2}$, Rory E. Morty ${ }^{1,2}$ (D) \\ and Katrin Ahlbrecht ${ }^{1,2^{*}}$
}

\begin{abstract}
Background: Gas exchange represents the key physiological function of the lung, and is dependent upon proper formation of the delicate alveolar structure. Malformation or destruction of the alveolar gas-exchange regions are key histopathological hallmarks of diseases such as bronchopulmonary dysplasia (BPD), chronic obstructive pulmonary disease (COPD), and pulmonary fibrosis; all of which are characterized by perturbations to the alveolo-capillary barrier structure. Impaired gas-exchange is the primary initial consequence of these perturbations, resulting in severe clinical symptoms, reduced quality of life, and death. The pronounced morbidity and mortality associated with malformation or destruction of alveoli underscores a pressing need for new therapeutic concepts. The re-induction of alveolarization in diseased lungs is a new and exciting concept in a regenerative medicine approach to manage pulmonary diseases that are characterized by an absence of alveoli.

Main text: Mechanisms of alveolarization first need to be understood, to identify pathways and mediators that may be exploited to drive the induction of alveolarization in the diseased lung. With this in mind, a variety of candidate cell-types, pathways, and molecular mediators have recently been identified. Using lineage tracing approaches and lung injury models, new progenitor cells for epithelial and mesenchymal cell types - as well as cell lineages which are able to acquire stem cell properties - have been discovered. However, the underlying mechanisms that orchestrate the complex process of lung alveolar septation remain largely unknown.

Conclusion: While important progress has been made, further characterization of the contributing cell-types, the cell type-specific molecular signatures, and the time-dependent chemical and mechanical processes in the developing, adult and diseased lung is needed in order to implement a regenerative therapeutic approach for pulmonary diseases.
\end{abstract}

Keywords: Alveolarization, Neo-alveolarization, Regeneration

\section{Background}

Therapeutic options for diseases that cause perturbations to the lung structure such as bronchopulmonary dysplasia (BPD), chronic obstructive pulmonary disease (COPD), and pulmonary fibrosis, are limited; and as such, new therapeutic concepts are needed [1-4]. A translational regenerative approach represents one future promising option for the development of new therapeutic concepts. In this approach, the identification of

\footnotetext{
* Correspondence: katrin.ahlbrecht@mpi-bn.mpg.de

${ }^{1}$ Member of the German Lung Research Center (DZL), Department of Lung Development and Remodelling, Max Planck Institute for Heart and Lung Research, Parkstrasse 1, 61231 Bad Nauheim, Germany

${ }^{2}$ Member of the German Lung Research Center (DZL), Department of Internal Medicine (Pulmonology), University of Giessen and Marburg Lung Center (UGMLC), Klinistrasse 33, 35392 Giessen, Germany
}

key molecular and cellular drivers of alveolarization and neo-alveolarization would be used to induce regeneration of alveoli in the diseased lung. The aim of this review is to provide an overview of recent developments in the underlying concepts of alveolarization and neo-alveolarization, and to explain how this knowledge might be used to induce regeneration of alveoli. Furthermore, techniques currently available to approach this question are highlighted. Current knowledge of alveolarization and neo-alveolarization includes consideration of the contributing cell-types, extracellular matrix (ECM) components and selected molecular mediators [5-14]. However, studies that have assessed cell-lineage specification, progenitor- or stem-cell characteristics, and molecular signatures in relation to the localization of a cell are limited. Future directions for research supporting

(c) The Author(s). 2018 Open Access This article is distributed under the terms of the Creative Commons Attribution 4.0 International License (http://creativecommons.org/licenses/by/4.0/), which permits unrestricted use, distribution, and 
this regenerative approach remain a crucial topic to be discussed, and likely directions are highlighted in the last paragraph of this review.

\section{Main text \\ Alveolarization}

Alveolarization represents a process during lung development that leads to the formation and maturation of the distal parts of the lung: the alveoli. In rats and mice, alveolarization takes place postnatally, whereas in humans, alveolar development begins prior to birth [3, 15-20]. Due to the limited availability of human tissue, most of the studies dissecting the principles of alveolarization have been conducted in rodents. At birth, the murine lung is in the saccular stage, which lasts from embryonic day (E)18.5 until postnatal day (P)5 [5], and which is comparable to the stage of lung development in which most pre-term born human infants are undergoing at the time of premature rupture of membranes. As such, term-born mouse and rats are often used to model the lung in pre-term born infants, with the important caveat that these lungs are perfectly competent for effective gas exchange at birth, contrasting with the situation in pre-term born human infants.
Nature of alveolar epithelial cells during the saccular stage and alveolarization

During the saccular stage of lung development, distal parts of the lung contain air sacs (sacculi or saccules) which are lined with an epithelial layer that originates from the foregut endoderm, and consists of differentiated alveolar epithelial type I cells (AECI) and alveolar epithelial type II cells (AECII) [5]. During the saccular stage, AECl and AECII are derived from a common bipotent progenitor cell (Fig. 1) [21]. As described in a later section of this review, mechanical forces and fibroblast growth factor (FGF) 10 are amongst recently-identified regulators of this differentiation process [22-24]. After alveolarization, and in the adult lung, AECII acquire stem cell properties and are capable of self-renewal to replace $\mathrm{AECl}$ after injury [21, 25]. Single-cell sequencing of distal lung epithelial cells during the saccular stage confirmed a bipotent progenitor for $\mathrm{AECl}$ and $\mathrm{AECll}$ and revealed further cell-type specific markers and subpopulations during the process of differentiation [26]. Cuboidal AECII cells are capable of producing surfactant proteins and lipids which decrease the surface tension of the alveoli [5, 27]. The cell surface of squamous $\mathrm{AECl}$ expands drastically during the alveolar stage [28]. One AECl covers multiple alveoli during

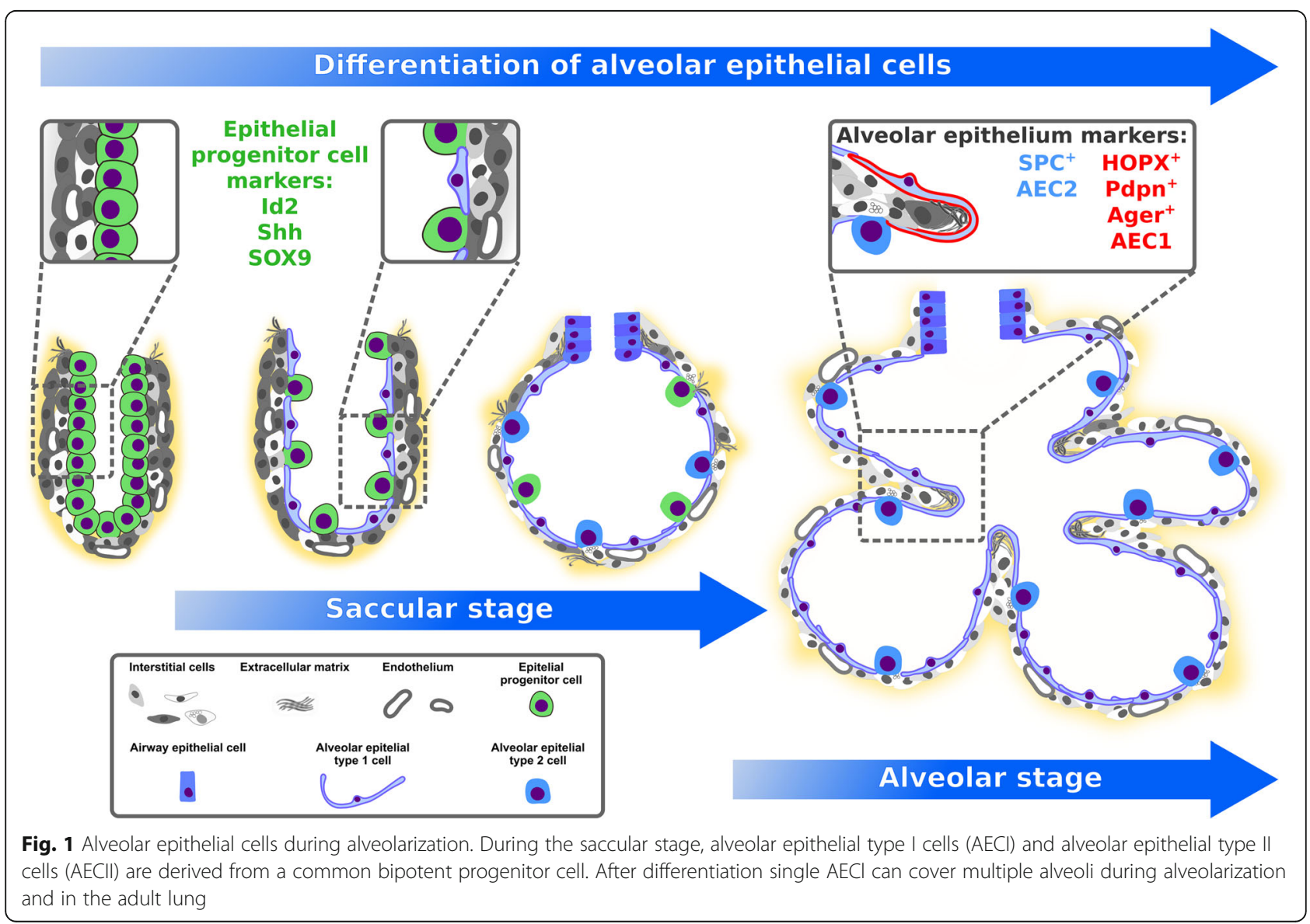


alveolarization and in the adult lung (Fig. 1) [28-30]. Due to the close proximity of AECI to the capillary network, and the comparatively larger surface area when compared to AECII, AECl represent the site of gas exchange [30].

\section{Role of mesenchymal cells and extracellular matrix during alveolarization}

Further components of the alveolar air-sac walls (primary septa) are endothelial cells that originate from the lung endoderm [8,31,32], and a variety of interstitial cell-types such as fibroblasts, which originate from the lung mesoderm $[8,33-35]$. In rat lung fibroblasts, an increase in retinoic acid levels has been demonstrated during secondary septation [36], and retinoic acid has been proposed to impact elastin production [36]. These studies highlighted a potential regenerative activity of retinoids in the lung. Retinoic acid administration to rats has been demonstrated to promote postnatal alveolarization, and to attenuate elastase-induced pulmonary emphysema [37, 38]. During the saccular stage, elastin expression increases, and elastin deposition by fibroblasts takes place [39]. In rodents, by P4, so-called secondary septa appear in the primary septa at sites of elastin deposition [5, 31]. At the tip (secondary crest) of these still-immature secondary septa, $\alpha$-smooth muscle actin $(\alpha S M A)^{+}$myofibroblasts appear, and the expression of ECM components such as elastin further increases (Fig. 2) [5, 6, 33, 39]. One recent study has carefully dissected structural changes in the developing alveoli, and elastin localization during alveolarization, using 3D imaging techniques [14]. These analyses pointed out that secondary crests arise as ridges into the alveolar air-sac lumen. An organized network resembling a "fishnet" composed of $\alpha$ SMA and the ECM component elastin runs within the ridges [14]. Quite similar observations were made in a further study that analyzed the spatial and temporal changes in elastin and laminin distribution during alveolarization [40]. That study demonstrated that elastin fibers formed ring-like structures which were localized to the saccular openings, and later on were interconnected by further elastin fibers [40]. Crosslinking of ECM components has been demonstrated to be altered during aberrant lung development [41]. The downstream signaling molecule of the sonic hedgehog pathway, Gli-1, has been demonstrated to label a cell-lineage which gives rise to secondary crest myofibroblasts (Fig. 2) [42-44]. The deposition of ECM components and the presence of alveolar myofibroblasts seems to be an attribute for secondary septation and has been demonstrated to be dependent on platelet-derived growth factor (PDGF)-A signaling [6, 45]. The ligand PDGF-A is produced by epithelial cells and signals via the cognate receptor PDGF receptor (PDGFR) $\alpha$, which is expressed by mesenchymal cells $[6,46,47]$. In vivo

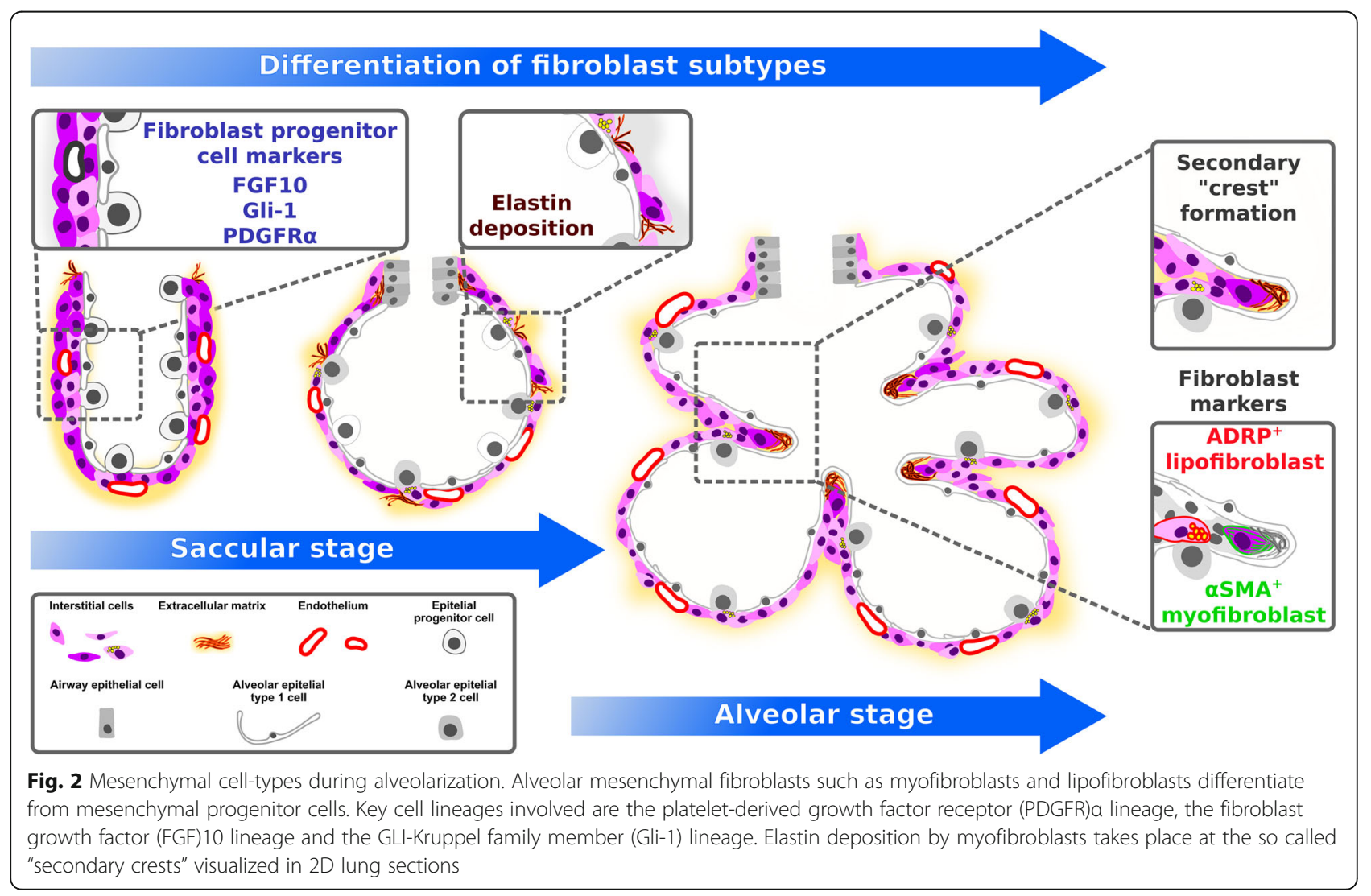


labeling and lineage-tracing studies of PDGFR $\alpha^{+}$cells have demonstrated that pulmonary PDGFR $\alpha^{+}$cells serve as progenitor cells for peribronchial and alveolar myofibroblasts, as well as for a proportion of the pulmonary lipofibroblasts, and are present in the primary and secondary septa (Fig. 2) $[6,45,48,49]$. Further studies have highlighted the progenitor nature of PDGFR $\alpha^{+}$cells for peribronchial smooth muscle cells, myofibroblasts and lipofibroblasts during prenatal lung development and alveolarization using time-series RNA-Seq analyses and immunophenotyping [50, 51]. Another recent study has described the spatiotemporal distribution of PDGFR $\alpha$ and the two PDGF ligands PDGF-A and PDGF-C over the course of lung development [52]. Expression of the ligands was detected in epithelial and smooth muscle cells, whereas the expression of PDGFR $\alpha$ was located to different mesenchymal cell populations [52], which is consistent with the prevailing view that epithelial-mesenchymal interactions are key mediators of lung development.

\section{Possible role for lipogenic versus myogenic fibroblast phenotypes during alveolarization}

Lipofibroblasts are also located within the primary and secondary septa in close proximity to AECII $[48,49,53]$. Lipid droplets and the expression of adipocyte differentiation related protein (ADRP, encoded by the Plin2 gene) represent phenotypic characteristics of lipofibroblasts
[53-57]. Further molecules such as peroxisome proliferator-activated receptor (PPAR) $\gamma$, cellular retinoic acid binding protein (CRABP), and the transcription factor TCF21 are expressed by lung mesenchymal lipofibroblasts (Fig. 3) [36, 58-61]. Lineage-tracing of FGF10 ${ }^{+}$cells revealed labeling of a subset of the lipofibroblast population [62]. Furthermore, lipofibroblasts have been demonstrated to support the synthesis of surfactant in AECII by providing triacylglycerols to AECII in a leptin- and stretch-dependent manner (Fig. 3) [53, 63]. During the period of secondary septation, the number of lipofibroblasts has been demonstrated to increase and peak at the same time as the peak of secondary septation, at P7 [64]. Activation of PPARy using rosiglitazone (which promotes the lipofibroblast phenotype) in rat pre- and post-natally has been demonstrated to be protective against the structural changes that occur during the development of hyperoxia-induced lung injury $[65,66]$. However, the presence of lipofibroblasts in the human lung remains controversial $[54,57,67]$. In contrast to rosiglitazone, which induces a lipogenic phenotype; Other reagents, stimuli and factors such as nicotine, mechanical forces, PDGFR $\alpha$ and transforming growth factor (TGF)- $\beta$ have been demonstrated to induce a myogenic phenotype: nicotine treatment of isolated fibroblasts in vitro led to a myogenic phenotype (differentiation from lipofibroblasts to myofibroblasts) and could be reversed by rosiglitazone treatment [68]. Furthermore it has been demonstrated that

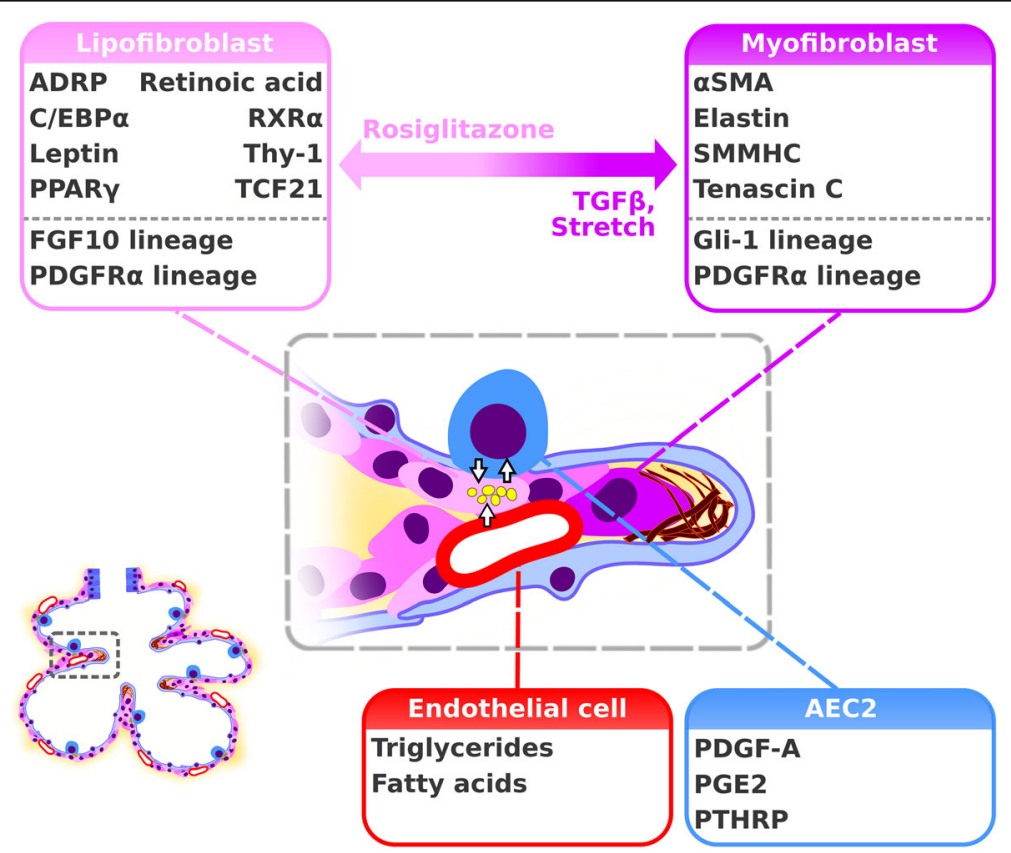

Fig. 3 Lipogenic versus myogenic fibroblast phenotype. Lipogenic (lipofibroblast) and myogenic (myofibroblast) fibroblasts differentiate during early lung development and the saccular stage. Lipofibrobasts support alveolar epithelial type II cells (AECII) cell function via an intercellular crosstalk mediated by stretch, parathyroid hormone-related peptide (PTHRP), prostaglandin E2 (PGE2) and leptin while myofibroblasts produce extracellular matrix molecules such as elastin. Activation of peroxisome proliferator activated receptor (PPAR)y by Rosiglitazone promotes the lipogenic phenotype. Stretch and transforming growth factor (TGF)- $\beta$ induce the myogenic phenotype 
mechanical forces could stimulate the differentiation of fibroblasts towards myofibroblasts (Fig. 3) [69]. Expression and activation of PDGFR $\alpha$ has also been demonstrated be involved in driving fibroblast differentiation towards a myogenic phenotype $[6,49,70]$. The expression of the PDGFR $\alpha$ chain has been demonstrated to be regulated by TGF- $\beta$ (Fig. 3) [71]. A very recent study has also carefully dissected the role of the ligand PDGF-A using mice carrying a floxed Pdgfr $\alpha$ allele in combination with a Sftpc-Cre mouse strain [72]. The authors demonstrated that PDGF-A was needed for myofibroblast formation and proliferation as well as for the regulation of AECII proliferation [72]. Taken together, tightly regulated differentiation of alveolar fibroblasts towards the myogenic or the lipogenic phenotype seems to be relevant for secondary septation. Furthermore, neuropillin 1 has been demonstrated to impact the PDGF-A axis via activation of Src kinases and to be required for alveolar mesenchymal cell migration [73]. Following this line, a reduced expression of PDGFR $\alpha$ and PDGFR $\beta$ has been demonstrated in mesenchymal cells of infants who develop BPD [74]. Furthermore, the signaling via FGF members has been demonstrated to impact the formation of myofibroblasts from PDGFR $\alpha^{+}$cells, as well as alveolar regeneration per se [75]. Deficiency of FGF10 has been demonstrated to be causative for the lethality in a mouse model of BPD [76]. Another mediator, Thy-1, which is expressed on lymphocytes and fibroblasts, has been demonstrated to severely impact alveolarization: an arrest of alveolarization itself has been demonstrated upon global loss of Thy-1 (CD90) [7]. The glycoprotein Thy- 1 inhibits TGF- $\beta$ activation, which leads to a reduced myogenic phenotype [7]. Since Thy-1 also is expressed on lipofibroblasts it might represent a molecule impacting on the balanced appearance of lipogenic and myogenic fibroblasts during secondary septation (Fig. 3) $[7,48]$. However, the role of leucocytes might be of relevance since inflammatory cells have been proposed to play a role - and to be present - during lung development [77], and resident alveolar macrophages have recently been implicated as master regulators of arrested lung development [78]. Apart from the role of lipogenic and myogenic phenotypes of fibroblasts in lung development, lipogenic and myogenic fibroblast phenotypes are also involved in the progression and resolution of pulmonary fibrosis, which has been demonstrated in a murine model of bleomycin-induced lung fibrosis [79]. This mechanism supports the hypothesis that understanding the nature and development of lipogenic versus myogenic fibroblast phenotypic transformation might help to develop new therapeutic strategies for pulmonary diseases.

\section{Epithelial-mesenchymal interactions during alveolarization}

The Interaction between mesenchymal and epithelial cells has been demonstrated to be essential for cellular differentiation and function during alveolarization. The formation of alveolospheres by alveolar epithelial cells (AEC) has been demonstrated to be supported by PDGFR $\alpha^{+}$cells in vitro [25]. In line with these findings, a mesenchymal cell population from the Axin2 cell-lineage which expressed PDGFR $\alpha$ has been demonstrated to support AECI and AECII differentiation and function [12]. In contrast, a rare population of AECII which express Axin2 has been demonstrated to have alveolar stem cell activity in the adult lung and to be supported by juxtacrine Wnt signals from neighboring fibroblasts during homeostasis, and autocrine Wnt signals upon severe injury [80]. Further evidence for mesenchymal-epithelial interactions being key drivers of cell differentiation during alveolar development has emerged from analyses comparing two distinct mesenchymal cell populations of the leucine-rich repeat-containing $G$ protein-coupled receptor (LGR) 5 and LGR6 cell lineage: the LGR5 and LGR6 lineages have been demonstrated to support cell function and differentiation of either alveolar or bronchiolar epithelial cells [13]. Furthermore human alveolar fibroblasts have been demonstrated to exhibit direct intercellular contact with AECl, AECll, capillaries and pericytes [81]. This strategic localization might position fibroblasts to mediate crosstalk between the epithelial and the capillary endothelial cells, as well as epithelial-mesenchymal interactions which are key drivers of cellular differentiation and function during alveolarization.

\section{Significance of mechanical forces in alveolarization}

Further key drivers of cellular processes that promote alveolarization are mechanical forces. An understanding of lung alveolarization is based primarily on understanding processes such as cellular differentiation, localization, production of ECM molecules and underlying signaling cascades. However, the impact of mechanical forces on these processes has been analyzed in the context of intercellular crosstalk and the differentiation of alveolar epithelial cells [22-24, 63, 82]. Surfactant production of AECII has been demonstrated to be stretch-dependent via a stretch-induced de novo synthesis of phosphatidyl choline by AECII [63]. Furthermore, stretch-dependent interactions with fibroblasts via parathyroid hormone-related peptide (PTHRP), prostaglandin E2 (PGE2) and fibroblast-derived leptin increased surfactant synthesis (Fig. 3) [63, 82]. A very recent study carefully dissected the role of mechanical forces on alveolar epithelial cell differentiation using live imaging techniques [23]. Mechanical forces generated by inhalation of amniotic fluid by prenatal breathing movements were essential for the differentiation of AECI [23]. Furthermore FGF10/FGFR2 signaling has been demonstrated to prevent flattening of alveolar progenitor cells, protecting AECII differentiation [23]. Mechanical forces have also been demonstrated to impact airway tube 
morphogenesis by controlling cell shape and orientation of cell division of the airway epithelium [22]. Taken together, mechanical forces induced by pre- and post-natal breathing movements are essential for cellular differentiation processes of epithelial and mesenchymal cells during alveolarization.

\section{Different types of alveolarization and maturation of the secondary septum}

Analyses of the temporal dynamics of the lung transcriptome during lung development revealed that changes in the transcriptome profiles confirmed previously defined stages of lung development [83]. Additionally, four stages of postnatal alveolar development were suggested based on the temporal changes in the lung transcriptome [83]. Similarities and contrasts of developmental processes and processes regulating disease and tissue homeostasis in the adult lung await to be dissected. For example, in contrast to the "classical or bulk alveolarization" which is initiated from an immature primary septum, "continued alveolarization" has been demonstrated starting from a more mature septum from P14 [31]. Maturation of the immature secondary septa by thinning of the septa and remodeling of double capillary networks to a single capillary network occurs during the stage of microvascular maturation starting at P12 [31]. During the stage of microvascular maturation, the laminin network has been demonstrated to be simplified, to ensure septal thinning [40]. During the last period of septal maturation by P21 mature septa appear next to continued alveolarization until young adulthood [31]. Taken together, understanding processes driving different types of alveolarization and the maturation of the alveolar septum might help to identify cellular and molecular drivers for each period, which might be used to induce regeneration of the alveolus in the diseased lung in which either regrowth or thinning of the alveolar wall is required.

\section{Conclusion alveolarization}

Different cell-types contributing to secondary septation have been identified, but distinct cell-type specific functions against the background of chemical and mechanical conditions during lung development still need to be understood. Identification of progenitor cells and a detailed characterization of the differentiation and function of mesenchymal lineages are needed to better understand secondary septation. Furthermore, understanding the function of AECll and AECl during secondary septation, and mapping the molecular signatures of the interactions between alveolar mesenchymal and epithelial cells might provide further insights into the nature of alveolar septation.

\section{Neo alveolarization}

The formation of new alveoli in the adult lung has been demonstrated in a variety of species including humans, after removal of a part of the lung (by pneumonectomy, PNX) [84-87]. In mice, left-sided PNX leads to a complete restoration of the mass-specific lung volume and total alveolar surface area within 21 days after the operation [86]. In humans, there is evidence for compensatory lung growth after PNX, but the time-course is months to years and a complete restoration of the lung capacity has not been demonstrated [84]. Some underlying mechanisms contributing to compensatory lung growth have been demonstrated in rodents, such as mediators of the alveolar stem cell niche and of vascular- epithelial interactions and will be discussed in the following paragraphs.

Nature of alveolar epithelial cells during neo-alveolarization In adult mice it has been demonstrated that HOPX1 lineage-labeled $\mathrm{AECl}$ expressed surfactant protein $\mathrm{C}$ (SPC) 21 days after PNX suggesting the generation of AECll from $\mathrm{AECl}$ during neo-alveolarization after PNX [10]. Furthermore a $\mathrm{SPC}^{-} \mathrm{AEC}$ progenitor cell pool has been identified in an in vivo embryonic lung organoid assay in mice suggesting a further progenitor cell-lineage for AECII [88]. However there is strong evidence based on lineage tracing approaches that AECll hold stem cell features in the adult and postnatal lung [21,25]. A further very recent study carefully dissected the role of bone morphogenic protein (BMP) signaling during alveolar regeneration in organoid culture and in vivo during the PNX model [89]. In the alveolar stem cell niche which, consists of AECII and PDGFR $\alpha$-expressing fibroblasts [90], BMP signaling was demonstrated to regulate AECII support function of PDGFR $\alpha^{+}$fibroblasts and differentiation of AECI and AECII, as well as AECII proliferation and self-renewal [89].

\section{Role of the vascular system and vascular mediators during neo-alveolarization}

Similar to the bulk alveolarization that occurs during postnatal lung development, crest formation arising from preexisting septa involving capillaries and mesenchymal cells has been demonstrated using scanning electron microscopy of vascular casts after PNX [91]. Mechanisms driving neo-vascularization such as sprouting and intussusceptive angiogenesis resemble neo-vascularization during postnatal bulk alveolarization [91]. Platelet-derived stromal-cell-derived factor (SDF) has been demonstrated to impact AEC expansion and neo-alveolarization after PNX [9]. Likewise, the crosstalk between pulmonary capillary endothelial cells and AEC during neo-alveolarization after PNX has been demonstrated to involve vascular endothelial growth factor receptor (VEGFR)2, matrix metalloproteinase (MMP)-14 and epidermal growth factor 
receptor (EGFR) resulting in expansion of epithelial progenitor cells [92]. Taken together, growth of the vascular system, and vascular mediators and growth factors such as SDF-1 and VEGF-A, are further drivers of epithelial cell function during lung regrowth after PNX.

\section{Impact of mesenchymal cells, mechanical forces and innate lymphoid cells on neo-alveolarization}

Further key drivers of lung growth after PNX have been identified in mesenchymal lineages. There is evidence for the participation of PDGFR $\alpha^{+}$cells in compensatory lung regrowth [93, 94]. Gene expression profiling of postnatal and adult mouse lungs undergoing PNX revealed concordantly as well as variably regulated genes [95]. There is a growing body of evidence that features of bulk alveolarization occur during compensatory lung growth of the adult lung, but alternative mechanisms need to be considered in addition. Cell proliferation, change in mechanical forces, ECM remodeling and the activation of different signaling pathways have been demonstrated in response to PNX [86, 92, 95-97]. Finally, myeloid cells and type 2 innate lymphoid cells (ICL2) have been demonstrated to hold regenerative capacity during compensatory lung growth after PNX [11]. A variety of cellular and molecular factors impacting on neo-alveolarization after PNX has been identified. However, target molecules capable to initiate neoalveolarization have not been recognized. Further combined lineage tracing, lineage ablation and cell type specific loss or gain of function studies are needed to identify hierarchies and functions of cell types and signaling cascades driving neo-alveolarization in the adult lung.

\section{Models to approach lung regeneration}

The induction of neo-alveolarization in the diseased lung requires a detailed knowledge of the conditions which are necessary for alveolar septum formation. Therefore, the identification of suitable models to study alveolar septum formation is essential. Transgenic tools [98-100] and genome-wide screening approaches [83] have revealed a variety of contributing cellular and molecular candidates and thus represent suitable tools to elucidate relevant candidate drivers for alveolarization. Therefore, alveolariaztion and neo-alveolarization after PNX are currently analyzed primarily in mice in vivo. However, some disadvantages of both models remain, and these are discussed in the following sections.

\section{Analyzing alveolarization}

Mice represent a valuable tool to analyze the process of alveolarization since alveolarization largely takes place postnatally in mice. Advantages of analyzing alveolarization in vivo in mice are the possibility to perform cell-type specific and inducible lineage tracing, cell and gene modulation, as well as cell ablation based on the $\mathrm{CreER}^{\mathrm{T} 2} /$ loxP system [101]. Differentiation processes, stem cell features, and morphological appearance can be analyzed in combination with high quality imaging approaches. Even cell-lineage and single-cell sequencing analyses can be performed at different time-points of alveolarization. However, a key limitation of studying alveolarization in mice is the need to validate identified candidate cells and genes in human tissue, which has to be performed to ensure the ranslational value of the pathway identified. Furthermore, it remains to be discovered which candidates relevant for alveolarization in postnatal mice might also be relevant for lung regeneration. Taken together, analyzing alveolarization in mice in vivo represents a suitable model, but validation of candidate factors in human lung tissue and adult mouse lung tissue has to be considered.

\section{Elucidating neo-alveolarization using the PNX model}

Exploitation of the model of compensatory lung growth after PNX will provide a better understanding of the cellular and molecular mechanism driving neoalveolarization. Beneficial aspects of this model are represented by the possibility that the advantages of transgenic mice can be used as well. Furthermore, alveolar regrowth can be studied in the adult lung, which might be more directly relevant to lung regeneration of the adult lung. Like studying alveolarization in mice, a disadvantage of studying regrowth after PNX in mice also remains, that driving factors might be different in mice and humans. Furthermore, it has been demonstrated that strongest regrowth takes place in the cardiac lobe [86]. Therefore, it might be necessary to restrict analyses to the cardiac lobe.

\section{Perspectives}

A possible way to approach lung regeneration is to better understand the composition of contributing cell types, the molecular signature and plasticity of cells, and the ECM composition, which together drive alveolarization and neo-alveolarization in order to identify possible candidates for the induction of lung regeneration. Progenitor cells need to be identified. Single-cell genome-wide screening approaches lead to a broader and more complex understanding of cell lineages of different tissue compartments [26, 102]. Better characterization of endodermal and mesenchymal cell lineages including molecular signatures might provide new insights into the cellular hierarchy of alveolarization, and might reveal progenitor cell candidates. Detailed time-dependent lineage tracing and cell depletion approaches covering prenatal and postnatal periods is needed to discover cell type-specific commitment and function during alveolarization. Furthermore, there is need to 
understand if factors driving bulk alveolarization in the developing lung might also be capable of inducing neo-alveolarization in the adult lung. Cellular and molecular candidates ensuring the homeostasis of the adult lung tissue additionally might be relevant for neo-alveolarization. A further aspect to approach alveolar regeneration might include the impact of aging and senescence on lung homeostasis and repair. As an example, telomerase activity, which impacts on cellular senescence, has been demonstrated to be tissue specifically regulated in mice during development and aging [103]. This is relevant because lung-specific modulation of telomerase activity during lung development might reveal possible target candidates that impact lung regeneration. Furthermore, the identification of possible targets to lung-specifically modulate the process of aging might reveal targets for future therapeutic concepts. Regulation of the cell cycle represents a key mechanism for tissue homeostasis and development. Signal transduction programs of cellular senescence cause an irreversible cell cycle arrest and thus might crucially impact lung regeneration [104]. Apart from processes which drive alveolarization and neo-alveolarization, processes which drive pulmonary

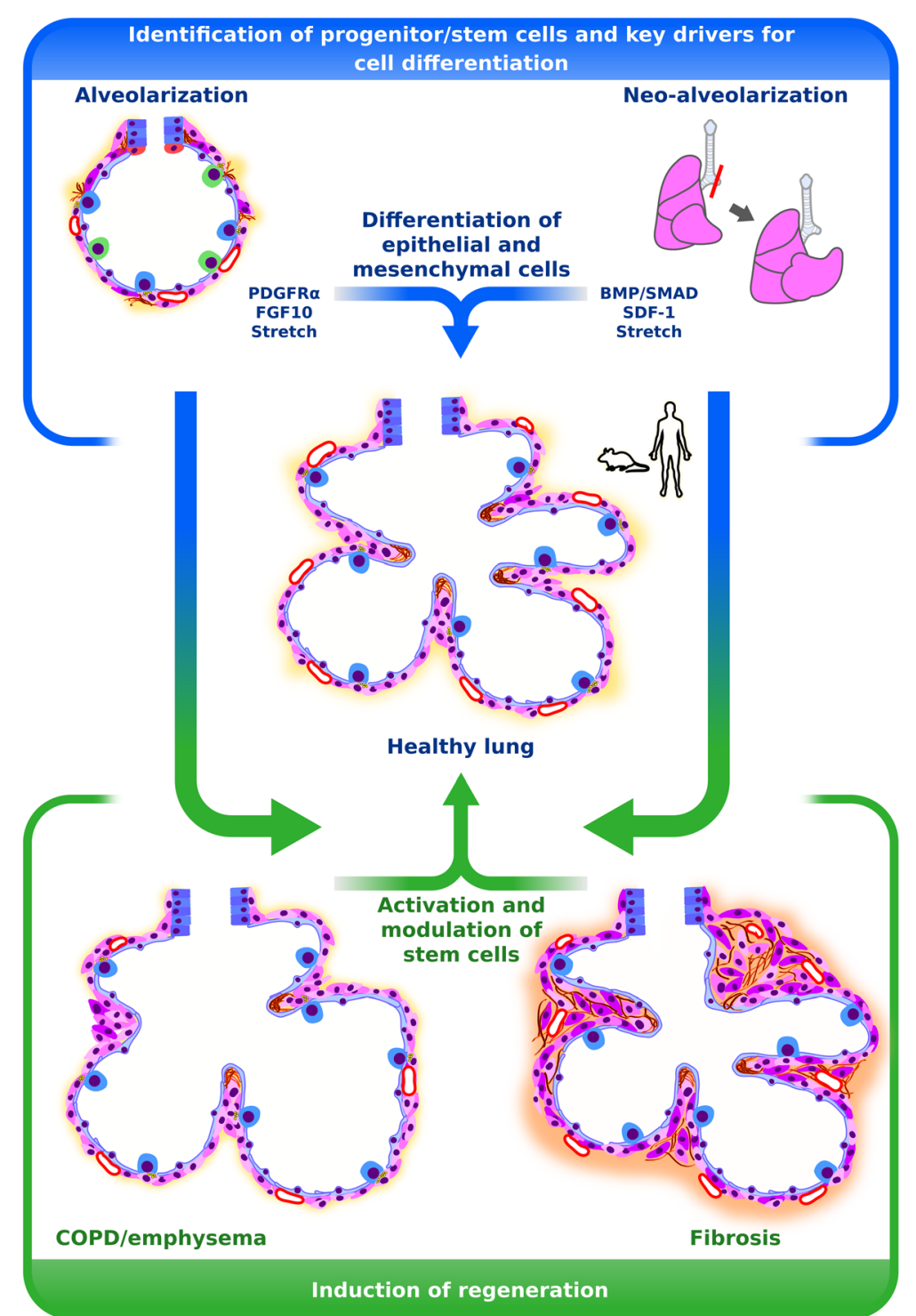

Fig. 4 Approaches for lung regeneration. Identification of progenitors or stem cells and mediators driving cellular differentiation during alveolarization and neo-alveolarization might be used to identify possible target candidates to induce regeneration during pulmonary diseases such as emphysema/chronic obstructive lung dsease and fibrosis. Promising target candidates are represented by platelet-derived growth factor receptor (PDGFR) $\mathrm{a}^{+}$cells and fibroblast growth factor (FGF)10 during alveolarization and bone morphogenic protein (BMP))/SMAD family member (SMAD) signaling and stromal cell derived factor (SDF)-1 during neo-alveolarization 
diseases have to be considered. Finally, target candidates identified in mice, need to be validated in human tissue.

\section{Conclusion}

Knowledge about alveolarisation and neo-alveolarization will reveal cellular and molecular target candidates that might be exploited for the development of new therapeutic concepts for pulmonary structural diseases. To explore cellular and molecular mediators of alveolarization and neo-alveolarization in vivo, suitable tools such as lineage tracing, cell-type specific cell-ablation techniques and cell-type specific molecular modulation, single cell sequencing and high quality $3 \mathrm{D}$ imaging approaches are currently available in mice. So far, concerning alveolarization, modulating the PDGFR $\alpha^{+}$cell-lineage which represents a member of the alveolar stem cell niche and modulating FGF10 which is involved in transducing mechanical forces seem to be promising approaches to modulate alveolarization (Fig. 4). The related candidate of the alveolar niche is represented by AECII. The stem cell function of AECII has been demonstrated to be essential for alveolar regrowth after PNX and has also been highlighted in this review. Identification of factors modulating stem cell functions of AECII and epithelial homeostasis such as BMP/SMAD signaling and SDF-1 represent the most promising approach to understand lung regrowth after PNX and further to develop strategies to induce lung regeneration during pulmonary diseases such as emphysema/COPD and fibrosis (Fig. 4). However, validation of identified candidates and pathways in human material always has to be considered, to ensure the chance of developing new therapeutic concepts for pulmonary diseases in human.

\section{Abbreviations}

3D: Three dimensional; AECl: Alveolar epithelial type I cell; AECll: Alveolar epithelial type II cell; BPD: Bronchopulmonary dysplasia; CD90: Cluster of differentiation 90; COPD: Chronic obstructive lung disease; CRABP: Cellular retinoic acid binding protein; E: Embryonic day; ECM: Extracellular matrix; FGF: Fibroblast growth factor; Gli-1: GLI-Kruppel family member;

LGR: Leucine-rich repeat- containing G protein-coupled receptor; P: Postnatal day; PC: Phosphatidyl cholin; PDGF-A: Platelet-derived growth factor-A; PDGF-C: Platelet-derived growth factor-C; PDGFRa: Platelet-derived growth factor receptor-a; PGE2: Prostaglandine E2; PNX: Pneumonectomy; PPARY: Peroxisome proliferator activated receptor gamma; PTHRP: Parathyriod hormone related peptide; PTHRP: Parathyroid hormonerelated peptide; SDF-1: Stromal cell derived factor 1; SMAD: SMAD family member; SPC: Surfactant protein C; TCF21: Transcription factor 21; TGF: Transforming growth factor; Thy-1: Thymus cell antigen 1; aSMA: a-Smooth muscle actin

\section{Funding}

This study was supported by the Max Planck Society (all authors, DB, LN, REM, KA); the German Center for Lung Research (Deutsches Zentrum für Lungenforschung; DZL; all authors); the Federal Ministry of Higher Education, Research and the Arts of the State of Hessen LOEWE Programme through grant UGMLC, (all authors); Rhön Klinikum AG, through grants FI_66 (to REM) and FI_71 (to K.A.); and the German Research Foundation (Deutsche Forschungsgemeinschaft, DFG) through: Excellence Cluster EXC147 "Cardio-Pulmonary System" (to REM), Collaborative Research
Center SFB1213 (to REM), Clinical Research Unit KFL309 (to REM) and individual research grant Mo 1879/1 (to REM).

\section{Availability of data and materials \\ Not applicable.}

\section{Authors' contributions}

JARC, DPB, LN, REM, KA drafted manuscript; JARC, DPB, LN, KA prepared figure; JARC, DPB, LN, WS, REM, KA edited and revised manuscript; JARC, $D P B, L N, W S, R E M, K A$ approved final version of the manuscript.

Ethics approval and consent to participate

Not applicable.

\section{Consent for publication \\ Not applicable.}

\section{Competing interests}

The authors declare that they have no competing interests.

\section{Publisher's Note}

Springer Nature remains neutral with regard to jurisdictional claims in published maps and institutional affiliations.

Received: 14 February 2018 Accepted: 2 July 2018

Published online: 06 August 2018

\section{References}

1. Rabe KF, et al. Global strategy for the diagnosis, management, and prevention of chronic obstructive pulmonary disease: GOLD executive summary. Am J Respir Crit Care Med. 2007;176(6):532-55.

2. Kim DS, Collard HR, King TE Jr. Classification and natural history of the idiopathic interstitial pneumonias. Proc Am Thorac Soc. 2006;3(4):285-92.

3. Silva DM, et al. Recent advances in the mechanisms of lung alveolarization and the pathogenesis of bronchopulmonary dysplasia. Am J Physiol Lung Cell Mol Physiol. 2015;309(11):L1239-72.

4. Surate Solaligue DE, et al. Recent advances in our understanding of the mechanisms of late lung development and bronchopulmonary dysplasia. Am J Physiol Lung Cell Mol Physiol. 2017;313(6):L1101-53.

5. Morrisey EE, Hogan BL. Preparing for the first breath: genetic and cellular mechanisms in lung development. Dev Cell. 2010;18(1):8-23.

6. Bostrom $\mathrm{H}$, et al. PDGF-A signaling is a critical event in lung alveolar myofibroblast development and alveogenesis. Cell. 1996;85(6):863-73.

7. Nicola T, et al. Loss of Thy-1 inhibits alveolar development in the newborn mouse lung. Am J Physiol Lung Cell Mol Physiol. 2009;296(5):L738-50.

8. Hogan $\mathrm{BL}$, et al. Repair and regeneration of the respiratory system: complexity, plasticity, and mechanisms of lung stem cell function. Cell Stem Cell. 2014:15(2):123-38.

9. Rafii S, et al. Platelet-derived SDF-1 primes the pulmonary capillary vascular niche to drive lung alveolar regeneration. Nat Cell Biol. 2015;17(2):123-36.

10. Jain $\mathrm{R}$, et al. Plasticity of Hopx(+) type I alveolar cells to regenerate type II cells in the lung. Nat Commun. 2015;6:6727.

11. Lechner AJ, et al. Recruited monocytes and type 2 immunity promote lung regeneration following pneumonectomy. Cell Stem Cell. 2017;21(1): 120-134 e7.

12. Zepp JA, et al. Distinct mesenchymal lineages and niches promote epithelial self-renewal and Myofibrogenesis in the lung. Cell. 2017;170(6): $1134-1148$ e10.

13. Lee $\mathrm{JH}$, et al. Anatomically and functionally distinct lung mesenchymal populations marked by Lgr5 and Lgr6. Cell. 2017;170(6):1149-1163 e12.

14. Branchfield $\mathrm{K}$, et al. A three-dimensional study of alveologenesis in mouse lung. Dev Biol. 2016;409(2):429-41.

15. Burri PH. The postnatal growth of the rat lung. 3. Morphology. Anat Rec. 1974;180(1):77-98.

16. Burri PH, Dbaly J, Weibel ER. The postnatal growth of the rat lung. I. Morphometry. Anat Rec. 1974;178(4):711-30.

17. Amy RW, et al. Postnatal growth of the mouse lung. J Anat. 1977;124(Pt 1):131-51

18. Zeltner TB, Burri PH. The postnatal development and growth of the human lung. II. Morphology. Respir Physiol. 1987;67(3):269-82.

19. Zeltner TB, et al. The postnatal development and growth of the human lung. I. Morphometry. Respir Physiol. 1987;67(3):247-67. 
20. Madurga A, et al. Recent advances in late lung development and the pathogenesis of bronchopulmonary dysplasia. Am J Physiol Lung Cell Mol Physiol. 2013;305(12):L893-905.

21. Desai TJ, Brownfield DG, Krasnow MA. Alveolar progenitor and stem cells in lung development, renewal and cancer. Nature. 2014;507(7491):190-4.

22. Tang $Z$, et al. Mechanical forces program the orientation of cell division during airway tube morphogenesis. Dev Cell. 2018;44(3):313-325 e5.

23. Li J, et al. The strength of mechanical forces determines the differentiation of alveolar epithelial cells. Dev Cell. 2018;44(3):297-312 e5.

24. Hogan BLM. Integrating mechanical force into lung development. Dev Cell. 2018:44(3):273-5.

25. Barkauskas CE, et al. Type 2 alveolar cells are stem cells in adult lung. J Clin Invest. 2013;123(7):3025-36.

26. Treutlein $B$, et al. Reconstructing lineage hierarchies of the distal lung epithelium using single-cell RNA-seq. Nature. 2014;509(7500):371-5.

27. Whitsett JA, Wert SE, Weaver TE. Alveolar surfactant homeostasis and the pathogenesis of pulmonary disease. Annu Rev Med. 2010;61:105-19.

28. Yang J, et al. Development and plasticity of alveolar type 1 cells. Development. 2016;143:54-65.

29. Weibel ER. The mystery of "non-nucleated plates" in the alveolar epithelium of the lung explained. Acta Anat (Basel). 1971;78(3):425-43.

30. Weibel ER. On the tricks alveolar epithelial cells play to make a good lung. Am J Respir Crit Care Med. 2015;191(5):504-13.

31. Tschanz SA, et al. Rat lungs show a biphasic formation of new alveoli during postnatal development. J Appl Physiol (1985). 2014;117(1):89-95.

32. Yamamoto $H$, et al. Epithelial-vascular cross talk mediated by VEGF-A and HGF signaling directs primary septae formation during distal lung morphogenesis. Dev Biol. 2007;308(1):44-53.

33. Chao CM, et al. A breath of fresh air on the mesenchyme: impact of impaired mesenchymal development on the pathogenesis of bronchopulmonary dysplasia. Front Med (Lausanne). 2015;2:27.

34. Ruiz-Camp J, Morty RE. Divergent fibroblast growth factor signaling pathways in lung fibroblast subsets: where do we go from here? Am J Physiol Lung Cell Mol Physiol. 2015;309(8):L751-5.

35. Rinkevich $Y$, et al. Identification and prospective isolation of a mesothelial precursor lineage giving rise to smooth muscle cells and fibroblasts for mammalian internal organs, and their vasculature. Nat Cell Biol. 2012;14(12): 1251-60.

36. McGowan SE, Harvey CS, Jackson SK. Retinoids, retinoic acid receptors, and cytoplasmic retinoid binding proteins in perinatal rat lung fibroblasts. Am J Phys. 1995;269(4 Pt 1):L463-72.

37. Massaro GD, Massaro D. Postnatal treatment with retinoic acid increases the number of pulmonary alveoli in rats. Am J Phys. 1996;270(2 Pt 1):L305-10.

38. Massaro GD, Massaro D. Retinoic acid treatment abrogates elastase-induced pulmonary emphysema in rats. Nat Med. 1997;3(6):675-7.

39. Mizikova I, Morty RE. The extracellular matrix in bronchopulmonary dysplasia: target and source. Front Med (Lausanne). 2015;2:91.

40. Luo Y, et al. Spatial and temporal changes in extracellular elastin and laminin distribution during lung alveolar development. Sci Rep. 2018;8(1):8334.

41. Mizikova I, et al. Collagen and elastin cross-linking is altered during aberrant late lung development associated with hyperoxia. Am J Physiol Lung Cell Mol Physiol. 2015;308(11):L1145-58

42. Li C, et al. Progenitors of secondary crest myofibroblasts are developmentally committed in early lung mesoderm. Stem Cells. 2015;33(3):999-1012.

43. Kugler MC, et al. Sonic hedgehog signaling regulates Myofibroblast function during alveolar septum formation in murine postnatal lung. Am J Respir Cell Mol Biol. 2017:57(3):280-93.

44. Ahlfeld SK, Perl AK. A "GLI-tch" in alveolar Myofibroblast differentiation. Am J Respir Cell Mol Biol. 2017:57(3):261-2.

45. Lindahl $\mathrm{P}$, et al. Alveogenesis failure in PDGF-A-deficient mice is coupled to lack of distal spreading of alveolar smooth muscle cell progenitors during lung development. Development. 1997;124(20):3943-53.

46. Bostrom H, Gritli-Linde A, Betsholtz C. PDGF-A/PDGF alpha-receptor signaling is required for lung growth and the formation of alveoli but not for early lung branching morphogenesis. Dev Dyn. 2002;223(1):155-62

47. Andrae J, et al. Characterization of platelet-derived growth factor-a expression in mouse tissues using a lacZ knock-in approach. PLoS One. 2014:9(8):e105477.

48. Ntokou A, et al. Characterization of the platelet-derived growth factor receptor alpha-positive cell lineage during murine late lung development. Am J Physiol Lung Cell Mol Physiol. 2015;309(9):L942-58.
49. McGowan SE, et al. Platelet-derived growth factor receptor-alpha-expressing cells localize to the alveolar entry ring and have characteristics of myofibroblasts during pulmonary alveolar septal formation. Anat Rec (Hoboken). 2008:291(12):1649-61.

50. Endale $M$, et al. Dataset on transcriptional profiles and the developmental characteristics of PDGFRalpha expressing lung fibroblasts. Data Brief. 2017; 13:415-31.

51. Endale $M$, et al. Temporal, spatial, and phenotypical changes of PDGFRalpha expressing fibroblasts during late lung development. Dev Biol. 2017;425;161-75.

52. Gouveia L, Betsholtz C, Andrae J. Expression analysis of platelet-derived growth factor receptor alpha and its ligands in the developing mouse lung. Physiol Rep. 2017;5(6):1-12.

53. McGowan SE, Torday JS. The pulmonary lipofibroblast (lipid interstitial cell) and its contributions to alveolar development. Annu Rev Physiol. 1997;59:43-62.

54. Rehan VK, et al. Evidence for the presence of lipofibroblasts in human lung. Exp Lung Res. 2006;32(8):379-93.

55. Vaccaro C, Brody JS. Ultrastructure of developing alveoli. I. The role of the interstitial fibroblast. Anat Rec. 1978;192(4):467-79.

56. Imamura $\mathrm{M}$, et al. ADRP stimulates lipid accumulation and lipid droplet formation in murine fibroblasts. Am J Physiol Endocrinol Metab. 2002;283(4): E775-83.

57. Ahlbrecht K, McGowan SE. In search of the elusive lipofibroblast, in human lungs. Am J Physiol Lung Cell Mol Physiol. 2014;307:L605-8.

58. Varisco BM, et al. Thy-1 signals through PPARgamma to promote lipofibroblast differentiation in the developing lung. Am J Respir Cell Mol Biol. 2012:46(6):765-72.

59. McGowan SE, McCoy DM. Regulation of fibroblast lipid-storage and myofibroblast phenotypes during alveolar septation in mice. Am J Physiol Lung Cell Mol Physiol. 2014;307:L618-31.

60. McGowan SE, et al. Peroxisome proliferators alter lipid acquisition and elastin gene expression in neonatal rat lung fibroblasts. Am J Phys. 1997 273(6 Pt 1):L1249-57.

61. Acharya A, et al. Efficient inducible Cre-mediated recombination in Tcf21 cell lineages in the heart and kidney. Genesis. 2011:49(11):870-7.

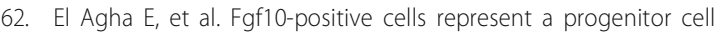
population during lung development and postnatally. Development. 2014;141(2):296-306.

63. Torday JS, Rehan VK. Stretch-stimulated surfactant synthesis is coordinated by the paracrine actions of PTHrP and leptin. Am J Physiol Lung Cell Mol Physiol. 2002;283(1):L130-5.

64. Maksvytis HJ, Vaccaro C, Brody JS. Isolation and characterization of the lipidcontaining interstitial cell from the developing rat lung. Lab Investig. 1981; 45(3):248-59.

65. Rehan VK, et al. Rosiglitazone, a peroxisome proliferator-activated receptorgamma agonist, prevents hyperoxia-induced neonatal rat lung injury in vivo. Pediatr Pulmonol. 2006;41(6):558-69.

66. Rehan VK, et al. Antenatally administered PPAR-gamma agonist rosiglitazone prevents hyperoxia-induced neonatal rat lung injury. Am J Physiol Lung Cell Mol Physiol. 2010;299(5):L672-80.

67. Tahedl D, et al. How common is the lipid body-containing interstitial cell in the mammalian lung? Am J Physiol Lung Cell Mol Physiol. 2014;307(5):L386-94.

68. Rehan VK, et al. Mechanism of nicotine-induced pulmonary fibroblast transdifferentiation. Am J Physiol Lung Cell Mol Physiol. 2005;289(4):L667-76.

69. Balestrini JL, et al. The mechanical memory of lung myofibroblasts. Integr Biol (Camb). 2012:4(4):410-21.

70. McGowan SE, McCoy DM. Fibroblasts expressing PDGF-receptor-alpha diminish during alveolar septal thinning in mice. Pediatr Res. 2011; 70(1):44-9.

71. Gronwald RG, Seifert RA, Bowen-Pope DF. Differential regulation of expression of two platelet-derived growth factor receptor subunits by transforming growth factor-beta. J Biol Chem. 1989;264(14):8120-5.

72. Gouveia L, Betsholtz C, Andrae J. PDGF-A signaling is required for secondary alveolar septation and controls epithelial proliferation in the developing lung. Development. 2018;145(7).

73. McGowan SE, McCoy DM. Neuropilin-1and platelet-derived growth factor receptors cooperatively regulate intermediate filaments and mesenchymal cell migration during alveolar septation. Am J Physiol Lung Cell Mol Physiol. 2018:315:L102-15.

74. Popova AP, et al. Reduced platelet-derived growth factor receptor expression is a primary feature of human bronchopulmonary dysplasia. Am J Physiol Lung Cell Mol Physiol. 2014;307(3):L231-9. 
75. Perl AK, Gale E. FGF signaling is required for myofibroblast differentiation during alveolar regeneration. Am J Physiol Lung Cell Mol Physiol. 2009; 297(2):L299-308.

76. Chao CM, et al. Fgf10 deficiency is causative for lethality in a mouse model of bronchopulmonary dysplasia. J Pathol. 2016;241:91-103.

77. Guilliams M, et al. Alveolar macrophages develop from fetal monocytes that differentiate into long-lived cells in the first week of life via GM-CSF. J Exp Med. 2013;210(10):1977-92.

78. Kalymbetova TV, et al. Resident alveolar macrophages are master regulators of arrested alveolarization in experimental bronchopulmonary dysplasia. J Pathol. 2018;245(2):153-9.

79. El Agha E, et al. Two-way conversion between Lipogenic and myogenic fibroblastic phenotypes marks the progression and resolution of lung fibrosis. Cell Stem Cell. 2016;20:261-73.

80. Nabhan AN, et al. Single-cell Wnt signaling niches maintain stemness of alveolar type 2 cells. Science. 2018;359(6380):1118-23.

81. Sirianni FE, Chu FS, Walker DC. Human alveolar wall fibroblasts directly link epithelial type 2 cells to capillary endothelium. Am J Respir Crit Care Med. 2003:168(12):1532-7.

82. Torday JS, et al. Leptin mediates the parathyroid hormone-related protein paracrine stimulation of fetal lung maturation. Am J Physiol Lung Cell Mol Physiol. 2002;282(3):L405-10.

83. Beauchemin KJ, et al. Temporal dynamics of the developing lung transcriptome in three common inbred strains of laboratory mice reveals multiple stages of postnatal alveolar development. PeerJ. 2016;4:e2318.

84. Butler JP, et al. Evidence for adult lung growth in humans. N Engl J Med. 2012;367(3):244-7.

85. Fehrenbach $\mathrm{H}$, et al. Neoalveolarisation contributes to compensatory lung growth following pneumonectomy in mice. Eur Respir J. 2008;31(3):515-22.

86. Voswinckel $R$, et al. Characterisation of post-pneumonectomy lung growth in adult mice. Eur Respir J. 2004;24(4):524-32.

87. Hsia CC, et al. Compensatory lung growth occurs in adult dogs after right pneumonectomy. J Clin Invest. 1994;94(1):405-12.

88. Chapman HA, et al. Integrin alpha6beta4 identifies an adult distal lung epithelial population with regenerative potential in mice. J Clin Invest. 2011; 121(7):2855-62.

89. Chung Ml, et al. Niche-mediated BMP/SMAD signaling regulates lung alveolar stem cell proliferation and differentiation. Development. 2018;145(9)

90. Hogan B. Stemming lung disease? N Engl J Med. 2018;378(25):2439-40.

91. Ackermann $\mathrm{M}$, et al. Sprouting and intussusceptive angiogenesis in postpneumonectomy lung growth: mechanisms of alveolar neovascularization. Angiogenesis. 2014;17(3):541-51.

92. Ding BS, et al. Endothelial-derived angiocrine signals induce and sustain regenerative lung alveolarization. Cell. 2011;147(3):539-53.

93. Chen $L$, et al. Dynamic regulation of platelet-derived growth factor receptor alpha expression in alveolar fibroblasts during realveolarization. Am J Respir Cell Mol Biol. 2012:47(4):517-27.

94. Green J, et al. Diversity of interstitial lung fibroblasts is regulated by PDGFRalpha kinase activity. Am J Respir Cell Mol Biol. 2016;54:532-45.

95. Wolff JC, et al. Comparative gene expression profiling of post-natal and post-pneumonectomy lung growth. Eur Respir J. 2010;35(3):655-66.

96. Kaza AK, et al. Epidermal growth factor augments postpneumonectomy lung growth. J Thorac Cardiovasc Surg. 2000;120(5):916-21.

97. Kaza AK, et al. Keratinocyte growth factor enhances post-pneumonectomy lung growth by alveolar proliferation. Circulation. 2002;106(12 Suppl 1):1120-4.

98. Swonger JM, et al. Genetic tools for identifying and manipulating fibroblasts in the mouse. Differentiation. 2016;92(3):66-83.

99. Ruiz-Camp J, et al. Tamoxifen dosing for Cre-mediated recombination in experimental bronchopulmonary dysplasia. Transgenic Res. 2017;26:165-70.

100. Ntokou A, et al. A novel mouse Cre-driver line targeting Perilipin 2expressing cells in the neonatal lung. Genesis. 2017;

101. Rawlins EL, Perl AK. The a "MAZE"ing world of lung-specific transgenic mice. Am J Respir Cell Mol Biol. 2012;46(3):269-82.

102. Rinkevich Y, et al. Skin fibrosis. Identification and isolation of a dermal lineage with intrinsic fibrogenic potential. Science. 2015;348(6232):aaa2151.

103. Prowse KR, Greider CW. Developmental and tissue-specific regulation of mouse telomerase and telomere length. Proc Natl Acad Sci U S A. 1995; 92(11):4818-22.

104. Kumar M, Seeger W, Voswinckel R. Senescence-associated secretory phenotype and its possible role in chronic obstructive pulmonary disease. Am J Respir Cell Mol Biol. 2014;51(3):323-33.

\section{Ready to submit your research? Choose BMC and benefit from:}

- fast, convenient online submission

- thorough peer review by experienced researchers in your field

- rapid publication on acceptance

- support for research data, including large and complex data types

- gold Open Access which fosters wider collaboration and increased citations

- maximum visibility for your research: over $100 \mathrm{M}$ website views per year

At BMC, research is always in progress.

Learn more biomedcentral.com/submissions 